news \& views

\title{
ERRATUM
}

\section{On our bookshelf}

Nature Physics 4, 827 (2008); published online: 3 November 2008; corrected after print: 14 December 2008.

In the version of this article originally published, the book Bose-Einstein Condensation in Dilute Gases was attributed to the wrong publisher; it should have read Cambridge University Press. This information has been corrected in the HTML and PDF versions. 